\title{
A serological survey of Bacillus anthracis reveals widespread exposure to the pathogen in free-range and captive lions in Zimbabwe.
}

Norman Mukarati ${ }^{1}$, Okechukwu Ndumnego ${ }^{2}$, Sunday Ochai ${ }^{3}$, Solomon Jauro ${ }^{3}$, Andrew Loveridge $^{4}$, Henriette van Heerden ${ }^{5}$, Gift Matope ${ }^{2}$, Alexandre Caron ${ }^{6}$, Tapiwanashe Hanyire $^{7}$, Michel de Garine-Wichatitsky ${ }^{8}$, and Davies Pfukenyi ${ }^{1}$

${ }^{1}$ University of Zimbabwe

${ }^{2}$ Affiliation not available

${ }^{3}$ University of Pretoria Faculty of Veterinary Science

${ }^{4}$ Oxford University

${ }^{5}$ University of Pretoria

${ }^{6}$ CIRAD - UR AGIRs

${ }^{7}$ Government of Zimbabwe Department of Livestock And Veterinary Services

${ }^{8}$ CIRAD

August 3, 2020

\begin{abstract}
Numerous unknown factors influence anthrax epidemiology in multi-host systems, especially at wildlife/livestock/human interfaces. Serology tests for anti-anthrax antibodies in carnivores are useful tools in identifying the presence or absence of Bacillus anthracis in a range. These were employed to ascertain if the disease pattern followed the recognized high and low risk anthrax zonation in Zimbabwe and also to establish if anthrax was absent from Hwange National Park in which there has been no reported outbreaks. African lions (Panthera leo) $(\mathrm{n}=114)$ drawn from -free-range protected areas and captive game parks located in recognized high and low risk zones across Zimbabwe were tested for antibodies to anthrax PA antigen using the ELISA immunoassay. A random selection of 27 lion sera samples comprising 17 sero-positive and 10 sero-negative sera were further tested in the species-independent toxin neutralization assay (TNA) in order to validate the former as a surveillance tool for anthrax in African lions. Using the ELISA-PA immunoassay, 21.9\% (25/114) of the lions tested positive for antibodies to anthrax. Seropositivity was recorded in all study areas and there was no significant difference $(\mathrm{p}=0.852)$ in seropositivity between lions in high and low risk anthrax zones. Also, there was no significant difference (McNemar's $\chi 2=0.9, \mathrm{p}=0.343$ ) in the proportion of lions testing positive to anti-PA anthrax antibodies on ELISA-PA immunoassay compared to the TNA, with fair agreement between the two tests $[$ Kappa $(K)$ statistic $=0.30 ; 0.08$
\end{abstract}

\section{Introduction}

Anthrax, caused by the Bacillus anthracis, a spore-forming Gram-positive bacterium, is a zoonotic disease of warm-blooded animals that can be fatal for livestock, wildlife and humans (Cote, Heffron, Bozue, \& Welkos, 2014; OIE, 2018; WHO, 2008). There are numerous unknown factors which influence the epidemiology of anthrax in multi-host systems, especially at wildlife/livestock/human interfaces. Anthrax induces fatal acute to peracute syndromes with no or little protective antibody immunity in herbivores. When present, protective 
antibody immunity often lasts less than a year in herbivores (de Vos \& Turnbull, 2004; Turnbull, Doganay, Aygen, Lindeque, \& Mclaughlin, 1992). However, carnivores, suids and humans are relatively resistant to anthrax with survivors or animals exposed to subclinical infections with $B$. anthracis mounting both celland antibody-mediated immunity. The duration of antibody reactivity to anthrax has been found to be much longer in surviving carnivores, and indefinite in humans (Bower et al., 2019; WHO, 2008; Turnbull et al., 1992). These attributes make carnivores ideal sentinel animals for the surveillance of anthrax in the multi-host system at the interface (Hampson et al., 2011; Mukarati et al., 2018). Indeed in Namibia, results of serological reactions to $B$. anthracis in wild carnivores were related to the occurrence of anthrax in herbivores in Etosha National Park, thus constituting an epidemiological tool for monitoring anthrax distribution (Turnbull et al., 1992).

Despite anthrax being considered endemic in some parts of Zimbabwe (Chikerema, Pfukenyi, Matope, \& Bhebhe, 2012; Mukarati et al., 2018), the epidemiology in wildlife is poorly understood due to suboptimal surveillance and outbreak investigations. Over the past 20 years to 2018, no overt anthrax outbreaks have been reported in wildlife in Hwange National Park (HNP) despite sporadic outbreaks of the disease in livestock in adjacent communal areas of Tsholotsho District to the South-East of the park (Mukarati et al., 2018). In this study, we gathered serum from 114 wild carnivores collected across high and low risk zones in Zimbabwe in order to explore the patterns of anthrax seropositivity in lions. More specifically, after validating our ELISA-based serology results using a non-species specific toxin neutralization test, we hypothesized that low risk areas for anthrax such as HNP with no reported wildlife anthrax outbreaks for 20 years to 2018 would result in significantly low seropositivity to anthrax in wild carnivores compared to high risk areas.

\section{Materials and methods}

African lion (Panthera leo ) serum samples $(\mathrm{n}=114)$ were obtained from serum banks from wild carnivore conservation projects in protected areas and recreational game parks in Zimbabwe. Each sample was allocated to high or low risk areas for anthrax (Figure 1, Table 1) based on a previous classification ( Chikerema, Murwira, Matope, \& Pfukenyi, 2013). The samples were collected from lions immobilized for various reasons over a period of 20 years $\left(1996\right.$ - 2016) and stored frozen at $-20^{\circ} \mathrm{C}$ at the Wildlife Unit of the Department of Veterinary Services, Ministry of Lands, Agriculture and Rural Resettlement, Zimbabwe. The 114 samples represented 114 different individuals. Demographic and other details of the lions used in this study were not included as the main objective was limited to determination of seropositivity according to low and high-risk anthrax zones.

The sera samples were tested for antibodies to B. anthraciscapsule (PA) antigen as detailed in Mukarati et al. (2018). A conventional PA ELISA was used to analyze samples for specific immunoglobulins according to (Hahn, Alex, Czerny, Böhm, \& Beyer, 2004) and modified by Ndumnego et al. (2013). For determination of the cut-off value for positive lion sera in the multi-species ELISA a similar approach depicted previously by Mukarati et al (2018) was adopted. Previously identified negative and positive control sera were sourced from a domestic cat presented for an unrelated condition at the Onderstepoort Veterinary Academic Hospital and from a vaccinated goat (Ndumnego, Koehler, Crafford, Beyer, \& van Heerden, 2018) respectively. Each ELISA plate contained duplicate wells of the known negative and positive control sera. Also six blank wells containing only the blocking solution (skimmed milk powder) were provided for each plate and background OD values from these wells were subtracted from the test sera wells. Seropositivity estimates of anthrax with $95 \%$ confidence intervals were computed using Stata Version SE/11. The primary sampling strata were the recognized high and low anthrax risk zones. Wildlife management systems (protected areas vs. recreational game parks), represented the secondary strata while the individual animals were the sampling units. Data analysis was done in Stata Version SE/11 for Windows (Stata Corp., College Station, USA) at a $95 \%$ confidence interval, and differences between strata noted.

The presence of anthrax-specific antibodies in lion sera using the ELISA-PA protocol was validated using a functional toxin neutralization assay (TNA). For this purpose, 27 randomly selected sera samples comprising 17 positive and 10 negative for anti-PA antibodies on ELISA-PA were further tested with TNA. The in vitro 
TNA was conducted using J774A.1 mouse macrophage cell line (ECACC cat no 91051511) with modifications as described (Hering et al., 2004; Ndumnego et al., 2018). The cell line was added at 100,000 cells in Dulbecco's modified eagle medium with $10 \%$ foetal bovine serum per well in flat-bottomed 96 -well culture plates (Corning , Germany) and allowed to incubate at $37^{\circ} \mathrm{C}$ in $5 \% \mathrm{CO}_{2}$ for 24 hours. Test sera were duplicated and diluted two-fold starting with a 1:50 PA $500 \mathrm{ng} / \mathrm{mL}$ in lethal factor (LF) $400 \mathrm{ng} / \mathrm{mL}$ (List Biological Laboratories Inc., USA). The mixture was incubated for 1 hour at $37^{\circ} \mathrm{C}$ before transferring to the previously seeded cells and incubated for 3 hours at $37^{\circ} \mathrm{C}$. Apart from the test sera added, each 96-well plate had blank wells dedicated to toxin ( 3 wells) and medium ( 2 wells) control while three wells were left blank. Each batch also contained a single dilution for the positive control obtained from a lion which was vaccinated with the Sterne live spore vaccine (Onderstepoort Biological Products, South Africa) to assess uniformity and duplicability of the assay. A $25 \mu \mathrm{L}$ of 3-(4,5 dimethylthiazol-2-yl)-2,5-diphenyltetrazolium bromide (Invitrogen, USA) was then added per well and the chromogenic mixture allowed to develop in darkness in a $\mathrm{CO}_{2}$ incubator at $37^{\circ} \mathrm{C}$ for 2 hours. Finally, a mixture of $90 \%$ isopropyl alcohol, $0.5 \%$ SDS and $25 \mathrm{mM} \mathrm{HCl}$ was added to all the wells to lyse the cells and the mixture further agitated by gentle pipetting several times before allowing it to rest for 5 minutes. The plates were then read at an absorbance of $570 \mathrm{~nm}$ in a Biotek power wave XS2 reader. The neutralization was calculated as:

Neutralization titre $(N T 50)=\frac{\text { Sample-Toxin control }}{\text { (Medium control-Toxin control }} X 100$

The Gen5 analysis software (Biotek Instruments, USA) was used to obtain the neutralization titres (NT50) which were conveyed as the corresponding value of the maximum dilution of the serum at which the antibodies protected $50 \%$ of the macrophages (NT50). Sera that could not protect up to $50 \%$ of the cells were recorded as having no anti-toxin neutralizing antibodies.

For the assay validation, the paired results for the 27 sera samples for ELISA and TNA assays were captured in SPSS, cross tabulated in a $2 \times 2$ contingency table and analysed for agreement using the McNemar's $\chi^{2}$ test (Adedokun \& Burgess, 2012) at 95\% confidence interval.

The geographic location data for sampled lions was used to create spatial distribution maps for seropositive animals across the country and in Hwange National Park. The maps were created in a GIS environment using ArcMap 10.1 (cite ArcMap 10.1) using location points for seropositive lions which were overlaid on shapefiles of administrative districts and wildlife conservation areas of Zimbabwe downloaded from www.divagis.org/gdata. Location points of positive cases in HNP were also overlaid on shapefile of the park to show the distribution.

\section{Results}

Based on the ELISA PA, 21.9\% (25/114) of African lions in this study tested positive for antibodies to anthrax (Table 1). Seropositivity was recorded in almost all the study areas except for the Antelope Game Park (Figure 1). A total of 5 lions $(22.7 \%, \mathrm{n}=22)$ from high-risk zones and 20 lions $(21.7 \%, \mathrm{n}=92)$ from low-risk zones respectively were positive for antibodies to anthrax PA antigen. However, the difference in seropositivity between the anthrax high- and low-risk zones was not significant $(\mathrm{p}=0.852)$ (Table 1). Similarly, seropositivity between free-range and captive lions was not significantly different $(\mathrm{p}=0.951)$ respectively at $22.6 \%(21 / 93)$ and $19.1 \%(4 / 21)$.

Figure 1. Map of Zimbabwe showing seroprevalence of anthrax in African lions sampled across the country.

With respect to lions in Hwange National Park which formed the bulk of the animals under this study, the sample distribution was biased towards the northern half of the park reflecting the spatial emphasis of the ongoing wild carnivore research projects from which the samples were drawn (Fig. 2). Seropositive lions were concentrated to the northeast part of HNP in areas which are adjacent to northern Tsholotsho (Ngamo) and Hwange Communal Lands although there were also positive lions far inland of HNP at about $90 \mathrm{~km}$ from the nearest park boundary.

Figure 2. Map of Hwange National Park (Zimbabwe) showing distribution of anthrax positive lions in sampled areas. 
The results for comparison of serological assays for anthrax in lions, namely ELISA anti-PA antibodies and TNA are given in Table 2. There was no significant difference in the proportion of lions testing positive for anti-PA anthrax antibodies by ELISA assay and by TNA $\left(\operatorname{McNemar}_{X}{ }^{2}\right.$ test $=0.9, \mathrm{p}=0.343$ at $95 \%$ significance level. The two tests had a fair agreement [Kappa $(\mathrm{K})$ statistic $=0.30 ; 0.08<\mathrm{K}<0.613$ ], thus, the null hypothesis was accepted and the TNA assay validated the ELISA anti-PA antibody assay used for screening lions in this survey.

\section{Discussion}

The anthrax PA, in addition to the oedema and lethal factors (EF and LF), make up the tripartite anthrax toxin complex (Schwartz 2009). These anthrax toxins are encoded by the anthrax-specific virulence plasmid, pXO1, with PA combining with LF to form the lethal toxin (LT). To date, no cross reacting antigens to anthrax PA are known and available data indicate anti-PA antibodies as being the most diagnostically stable (Leppla, Robbins, Schneerson, \& Shiloach, 2002; Turnbull et al., 1992). However, PA is antigenic complex and can elicit protective and non-protective antibodies. Abboud \& Casadevall (2008) investigated the relationship between PA structure and antigenicity but could only conclude the genetic background of the host determines the relative efficacy of the antitoxin response (Abboud \& Casadevall, 2008) and, thus the toxin reutilizing antibodies were determine on a random sample to verify the use of anti-PA antibodies in this study.

Both ELISA and toxin neutralization (TNA) assays can be used to detect antibodies to PA antigen in sera of animals exposed to B. anthracis . We report for the first time the dual existence of anthrax PA-specific and lethal toxin neutralizing antibodies in naturally exposed African lions. The TNA is a functional assay that measures the neutralizing activity of sub-sets of PA-specific antibodies against the cytotoxic effect of the lethal toxin complex formed by PA in association with LF. Though technically demanding, TNA confirms previous exposure to B. anthracis in animals and is species-independent (Ngundi, Meade, Lin, Tang, \& Burns, 2010; Omland et al., 2008; Savransky et al., 2017). On the other hand the ELISA assay detects antibodies to PA antigen in sera of infected individuals and is less demanding but well correlated with the TNA (Arciniega \& Domínguez-Castillo, 2011; Ndumnego, Crafford, Beyer, \& van Heerden, 2013; Parreiras, Sirota, Wagner, Menzies, \& Arciniega, 2009). Consequently, the use of ELISA immunoassays with PA as the sole antigen in diagnostic tests has been validated in humans (Ghosh et al., 2015; Quinn et al ., 2002; Semenova et al ., 2012), horses (Caldwell, Hathcock, \& Brock, 2017) and goats (Ndumnego et al ., 2013). In this study, we validated the use of the ELISA assay for detecting anthrax anti-PA antibodies in exposed African lions by using the TNA assay. Indeed, earlier researchers (Bagamian, Alexander, Hadfield, \& Blackburn, 2013; Hampson et al ., 2011; Switzer et al ., 2016; Turnbullet al ., 1992), have used the ELISA-PA assay to monitor $B$. anthracis exposure in lions among other carnivore species. Hence, the ELISA-PA immunoassay for the serological survey of $B$. anthracisexposure in African lions was adopted for use in this study.

Further, on the use of ELISA-PA assay in goats, Ndumnego et al . (2013) compared and observed that the use of skimmed milk powder gives a lower background reading compared to the use of foetal calf serum. While there may be the risk of lion IgG detecting milk or any other ruminant proteins leading to false positives, the presence of lethal toxin neutralizing antibodies in sero-positive sera in toxin neutralization test negates this. The presence of anti-PA antibodies in animals indicates that non-lethal systemic infection may have taken place (Hugh-Jones \& Blackburn, 2009; Ndumnego et al ., 2013; Turnbullet al ., 1992). Therefore based on anti-PA antigen antibodies serological assay in African lions, there were indications that B. anthracis pathogen was present with a wide distribution in Zimbabwe.

In the case of HNP where anthrax outbreaks have not been reported in over 20 years to 2018, this represents the first confirmation of the presence and wide exposure of $B$. anthracis to lions in the park. There is a possibility that some lions from HNP could have been exposed to anthrax from consumption of livestock carcasses as outbreaks of anthrax were reported in adjacent communal lands of Tsholotsho southeastern to HNP (Fig. 2) (Mukarati et al ., 2018).Indeed, predation of livestock by lions from the park is an established human-wildlife conflict issue in the area (Loveridge et al ., 2017). However, other seropositive lions were far removed from this community at more than $90 \mathrm{~km}$ from the nearest park boundary. This distance was well 
outside the lions' home range of about $20 \mathrm{~km}$ radius (Loveridge et al ., 2009) indicating unlikely influence of diseases between the lions and livestock. It is most likely that such seropositive lions were exposed to other sources of B. anthracisin HNP. Due to the limitation on samples available, the distribution of the positive lions was biased towards the northern half of the park. A uniform distribution of positive lion samples would have provided more insightful trends.

Although this was not strictly a cross-sectional survey in that the lions were sampled over 20 years, it nonetheless provides useful information. That lions sampled over this period were positive for $B$. anthracis in the absence of reported disease outbreaks suggests either occurrence of undetected outbreaks of the disease or sublethal infections in wildlife in HNP (Hugh-Jones and Blackburn, 2009; Cizauskas et al., 2014). Thus, the hitherto general belief that HNP was free of anthrax based on no reported cases is uncertain. The presence of antibodies to anthrax in lions in Mana Pools NP, Save Valley Conservancy and Malilangwe Wildlife Reserve indicates that $B$. anthracis was already circulating in the area long before the disease outbreaks occurred (Mukarati et al., 2018; Clegg et al.,2007; OIE, 1997). However, there was no correlation between anthrax outbreaks and seropositivity in lions from this dataset. Improved surveillance and additional studies on possible environmental and soil geochemical factors possibly influencing $B$. anthracisdistribution in protected areas are necessary (Hugh-Jones and Blackburn, 2009; Griffin et al., 2014).

There were no known anthrax outbreaks that could account for exposure and seroconversion in captive lions in this study. According to de Vos and Turnbull (2004), anthrax outbreaks affecting wildlife in captivity are limited to consumption of infected meat. Carnivores on small game parks are managed essentially as in zoological gardens and thus are presumably similarly exposed to anthrax. An anthrax outbreak occurred in lions and cheetahs in 1997 at Lion and Cheetah Park, Harare, when they were fed infected cattle meat donated by a farm (OIE, 1997). On the other hand, wild carnivores in captivity maybe exposed to $B$. anthracis from infected meat without necessarily developing clinical disease either due to their relative resistance or exposure to sublethal anthrax doses (Beyer and Turnbull, 2009; Hugh-Jones and Blackburn, 2009; Cizauskas et al ., 2014).

A pertinent question which arises is the specificity of the serological assay used in this survey, given that there are few reports of atypical $B$. cereus strains causing similar disease in humans and wild primates (Marston et al., 2016). Rare cases of anthrax-like illness in humans and wild chimpanzees caused by a $B$. cereusstrain possessing the anthrax toxin genes have been reported in the US and West Africa (Antonation et al ., 2016; Hoffmaster et al ., 2006; Klee et al ., 2006). However, to date there are no documented cases of outbreaks caused by this strain of $B$. cereusin wild or domestic ruminants, or the carnivores that predate on these animals. While not ruling out the possible exposure to environmental $B$. cereus in grazing animals, the presence of the rare toxin-producing $B$. cereus strains have not been reported in Southern Africa (Romeroalvarez et al., 2020). Thus, the seropositivity of lions in this study is assumed to be attributable to exposure to $B$. anthracis strains.

The finding of no significant difference in seropositivity between lions located in currently recognized highand low-risk zones for anthrax $(\mathrm{p}=0.852$, Table 1$)$ tally with earlier findings in domestic dogs (Mukaratiet al., 2018). A much wider range of anthrax endemic areas in Zimbabwe can be hypothesized similar to other endemic regions of the world. This suggests that the categorization of areas in Zimbabwe into high- and low-risk zones may not represent the true status of anthrax presence across the country. This needs review based on improved surveillance and epizootiological investigations. Anthrax serology in resident wild and/or domestic carnivores could serve as sentinel and indicator of anthrax circulation in given areas and thus can be useful epidemiological tools.

The widespread presence of anthrax antibodies in lions in protected areas, irrespective of absence of reported disease outbreaks in wild or domestic ungulates or humans, confirms a much larger circulation of $B$. anthracis in Zimbabwe. These results raise new questions on the epidemiology of anthrax in endemic regions. There is need to investigate local factors that could be associated with anthrax outbreaks apart from the presence of the pathogen. On the other hand, there could be smaller outbreaks of anthrax occurring but going unnoticed in HNP as has been noted elsewhere (Cizauskas, Bellan, Turner, Vance, \& Getz, 2014). Overall, improved 
surveillance of anthrax in all animals could shed more light on whether outbreaks were indeed taking place but being missed because of inadequate surveillance and may also give pointers on risk factors. Further, the spatial distribution of lions tested for anthrax anti-PA antibodies in this study in the northern half of HNP meant that insightful trends in the whole of the park could not be determined. A more uniform distribution of lion samples tested for anthrax anti-PA antibodies across the park would be helpful in establishing likely risk areas for the disease outbreaks.

\section{Author contributions}

Norman Leo Mukarati was the main researcher who conceived the ideas and designed the methodology as well as carrying out the field work and partly the laboratory work;

Okechukwu C. Ndumnego, Solomon Jauro and Henriette van Heerden designed, carried out the serological testing of the samples for B. anthracis PA antigen antibodies by ELISA -PA assay and revised final manuscript.

Sunday O. Ochai and Henriette van Heerdendesigned, carried out the toxin neutralization (TNA) test for validation of ELISA-PA assay for detection of antibodies to B. anthracis in lion sera, and also revised final manuscript.

Andrew Loveridge and Tapiwa G. Hanyire collected the blood samples from lions used in this study.

Davies M. Pfukenyi and Gift Matope carried out data analysis and redrafting of the manuscript especially epidemiological aspects.

Alexandre Caron and Michel de Garine-Wichatitsky -critiqued the manuscript and contributed to its redrafting.

\section{Acknowledgements}

This work was undertaken in the framework of the Research Platform "Production and Conservation in Partnership" (www.rp-pcp.org) and funded by the Ministère Français des Affaires Etrangères through the FSP-RenCaRe project (FSP n ${ }^{\circ}$ 2011/36). The University of Zimbabwe Research Board also contributed financially to this study. The authors would also like to thank the Hwange Lion Research Project/ Trans-Kalahari Predator Programme based in Hwange National Park, Zimbabwe who made available blood sera samples from lions in their conservation research project and Ms Jane Hunt for collection and facilitation of access to samples. Zimbabwe Parks and Wildlife Management Authority is gratefully acknowledged for allowing this publication.

\section{Conflict of interest}

None.

\section{Ethics statement}

The authors confirm that the ethical policies of the journal, as noted on the journal's author guidelines page, have been adhered to and the appropriate ethical review committee approval has been received. The Zimbabwe National Animal Research Committee's guidelines under Scientific Experiments on Animals Act (Chapter 19:12) were followed.

\section{Data availability statement}

The data that support the findings of this study are available from the corresponding author upon reasonable request.

\section{References}

Abboud, N., \& Casadevall, A. (2008). Immunogenicity of Bacillus anthracis protective antigen domains and efficacy of elicited antibody responses depend on host genetic background. Clinical and Vaccine Immunology , 15 (7), 1115-1123. https://doi.org/10.1128/CVI.00015-08 
Adedokun, O. A., \& Burgess, W. D. (2012). Analysis of Paired Dichotomous Data: A Gentle Introduction to the McNemar Test in SPSS .8 (17), 125-131.

Antonation, K. S., Grutzmacher, K., Dupke, S., Mabon, P., Zimmermann, F., Lankester, F., ... Leendertz, F. H. (2016). Bacillus cereus Biovar Anthracis Causing Anthrax in Sub-Saharan AfricaChromosomal Monophyly and Broad Geographic Distribution. PLoS Neglected Tropical Diseases , 10 (9). https://doi.org/10.1371/journal.pntd.0004923

Arciniega, J. L., \& Dominguez-Castillo, R. I. (2011). Development and validation of serological methods for human vaccine potency testing: Case study of an anthrax vaccine. Procedia in Vaccinology, 5 . https://doi.org/10.1016/j.provac.2011.10.021

Bagamian, K. H., Alexander, K. A., Hadfield, T. L., \& Blackburn, J. K. (2013). Ante- and postmortem diagnostic techniques for anthrax: Rethinking pathogen exposure and the geographic extent of the disease in wildlife. Journal of Wildlife Diseases , 49 (4), 786-801. https://doi.org/10.7589/2013-05-126

Bower, W. A., Schiffer, J., Atmar, R. L., Keitel, W. A., Friedlander, A. M., Liu, L., .. Hendricks, K. (2019). Use of anthrax vaccine in the United States: Recommendations of the advisory committee on immunization practices, 2019. MMWR Recommendations and Reports ,68 (4), 1-20. https://doi.org/10.15585/mmwr.rr6804a1

Caldwell, M., Hathcock, T., \& Brock, K. V. (2017). Passive protection against anthrax in mice with plasma derived from horses hyper-immunized against Bacillus anthracis Sterne strain. PeerJ , 2017 (12), 1-18. https://doi.org/10.7717/peerj.3907

Chikerema, S. M., Murwira, A., Matope, G., \& Pfukenyi, D. M. (2013). Spatial modelling of Bacillus anthracis ecological niche in Zimbabwe.Preventive Veterinary Medicine , 111 (1-2), 25-30. https://doi.org/10.1016/j.prevetmed.2013.04.006

Chikerema, Silvester Maravanyika, Pfukenyi, D. M., Matope, G., \& Bhebhe, E. (2012). Temporal and spatial distribution of cattle anthrax outbreaks in Zimbabwe between 1967 and 2006. Tropical Animal Health and Production , 44 (1), 63-70. https://doi.org/10.1007/s11250-011-9888-z

Cizauskas, C. A., Bellan, S. E., Turner, W. C., Vance, R. E., \& Getz, W. M. (2014). Frequent and seasonally variable sublethal anthrax infections are accompanied by short-lived immunity in an endemic system. Journal of Animal Ecology , 83 (5), 1078-1090. https://doi.org/10.1111/1365-2656.12207

Clegg, S. B., Turnbull, P. C. B., Foggin, C. M., \& Lindeque, P. M. (2007). Massive outbreak of anthrax in wildlife in the Malilangwe Wildlife Reserve, Zimbabwe. Veterinary Record , 160 (4), 113-118. https://doi.org/10.1136/vr.160.4.113

Cote, C. K., Heffron, J. D., Bozue, J. A., \& Welkos, S. L. (2014). Bacillus anthracis and Other Bacillus Species. In Molecular Medical Microbiology: Second Edition (Vol. 3, pp. 1789-1844). https://doi.org/10.1016/B978-0-12-397169-2.00102-5

de Vos, V., \& Turnbull, P. C. B. (2004). Anthrax. In Infectious diseases of livestock .

Ghosh, N., Gunti, D., Lukka, H., Reddy, B. R., Padmaja, J., \& Goel, A. K. (2015). Development \& validation of a quantitative anti-protective antigen IgG enzyme linked immunosorbent assay for serodiagnosis of cutaneous anthrax. Indian Journal of Medical Research ,142 (AUGUST), 196-204. https://doi.org/10.4103/0971-5916.164258

Hahn, U. K., Alex, M., Czerny, C. P., Bohm, R., \& Beyer, W. (2004). Protection of mice against challenge with Bacillus anthracis STI spores after DNA vaccination. International Journal of Medical Microbiology, 294 (1), 35-44. https://doi.org/10.1016/j.ijmm.2003.12.002

Hampson, K., Lembo, T., Bessell, P., Auty, H., Packer, C., Halliday, J., .. Cleaveland, S. (2011). Predictability of anthrax infection in the Serengeti, Tanzania. Journal of Applied Ecology ,48 (6), 1333-1344. 
https://doi.org/10.1111/j.1365-2664.2011.02030.x

Hering, D., Thompson, W., Hewetson, J., Little, S., Norris, S., \& Pace-Templeton, J. (2004). Validation of the anthrax lethal toxin neutralization assay. Biologicals , 32 (1), 17-27. https://doi.org/10.1016/j.biologicals.2003.09.003

Hoffmaster, A. R., Hill, K. K., Gee, J. E., Marston, C. K., De, B. K., Popovic, T., ... Jackson, P. J. (2006). Characterization of Bacillus cereus isolates associated with fatal pneumonias: Strains are closely related to Bacillus anthracis and Harbor B. anthracis virulence genes. Journal of Clinical Microbiology , 44 (9), 3352-3360. https://doi.org/10.1128/JCM.00561-06

Hugh-Jones, M., \& Blackburn, J. (2009). The ecology of Bacillus anthracis. Molecular Aspects of Medicine , Vol. 30, pp. 356-367. https://doi.org/10.1016/j.mam.2009.08.003

Klee, S. R., Nattermann, H., Becker, S., Urban-Schriefer, M., Franz, T., Jacob, D., \& Appel, B. (2006). Evaluation of different methods to discriminate Bacillus anthracis from other bacteria of the Bacillus cereus group. Journal of Applied Microbiology , 100 (4), 673-681. https://doi.org/10.1111/j.1365-2672.2006.02809.x

Leppla, S. H., Robbins, J. B., Schneerson, R., \& Shiloach, J. (2002). Development of an improved vaccine for anthrax. Journal of Clinical Investigation , 110 (2), 141-144. https://doi.org/10.1172/JCI0216204

Loveridge, A. J., Kuiper, T., Parry, R. H., Sibanda, L., Hunt, J. H., Stapelkamp, B., .. Macdonald, D. W. (2017). Bells, bomas and beefsteak: Complex patterns of human-predator conflict at the wildlife-agropastoral interface in Zimbabwe. PeerJ ,2017 (1), 1-24. https://doi.org/10.7717/peerj.2898

Loveridge, A. J., Valeix, M., Davidson, Z., Murindagomo, F., Fritz, H., \& MacDonald, D. W. (2009). Changes in home range size of African lions in relation to pride size and prey biomass in a semi-arid savanna.Ecography , 32 (6), 953-962. https://doi.org/10.1111/j.1600-0587.2009.05745.x

MOORE, P. E. (1955). World Health Organization. Canadian Services Medical Journal , 11 (3), 121-126.

Mukarati, N. L., Ndumnego, O., Van Heerden, H., Ndhlovu, D. N., Matope, G., Caron, A., ... Pfukenyi, D. M. (2018). A serological survey of anthrax in domestic dogs in Zimbabwe: A potential tool for anthrax surveillance. Epidemiology and Infection , 146 (12). https://doi.org/10.1017/S0950268818001577

Ndumnego, O. C., Crafford, J., Beyer, W., \& van Heerden, H. (2013). Quantitative anti-PA IgG ELISA; assessment and comparability with the anthrax toxin neutralization assay in goats. BMC Veterinary Research , 9 . https://doi.org/10.1186/1746-6148-9-265

Ndumnego, O. C., Koehler, S. M., Crafford, J. E., Beyer, W., \& van Heerden, H. (2018). Immunogenicity of anthrax recombinant peptides and killed spores in goats and protective efficacy of immune sera in A/J mouse model. Scientific Reports , 8 (1), 1-10. https://doi.org/10.1038/s41598-018-35382-8

Ngundi, M. M., Meade, B. D., Lin, T. L., Tang, W. J., \& Burns, D. L. (2010). Comparison of three anthrax toxin neutralization assays.Clinical and Vaccine Immunology , 17 (6), 895-903. https://doi.org/10.1128/CVI.00513-09

Omland, K. S., Brys, A., Lansky, D., Clement, K., Lynn, F., Huber, N. T., ... Johnson, W. (2008). Interlaboratory comparison of results of an anthrax lethal toxin neutralization assay for assessment of functional antibodies in multiple species. Clinical and Vaccine Immunology , 15 (6), 946-953. https://doi.org/10.1128/CVI.00003-08

Parreiras, P. M., Sirota, L. A., Wagner, L. D., Menzies, S. L., \& Arciniega, J. L. (2009). Comparability of ELISA and toxin neutralization to measure immunogenicity of Protective Antigen in mice, as part of a potency test for anthrax vaccines. Vaccine, 27 (33), 4537-4542. https://doi.org/https://doi.org/10.1016/j.vaccine.2009.05.045

Quinn, C. P., Semenova, V. A., Elie, C. M., Romero-Steiner, S., Greene, C., Li, H., .. Perkins, B. A. (2002). Specific, sensitive, and quantitative enzyme-linked immunosorbent assay for human immunoglob- 
ulin G antibodies to anthrax toxin protective antigen. Emerging Infectious Diseases , 8 (10), 1103-1110. https://doi.org/10.3201/eid0810.020380

Romero-alvarez, D., Peterson, A. T., Salzer, J. S., Pittiglio, C., Shadomy, S., Id, R. T., .. Campbell, L. P. (2020). Potential distributions of Bacillus anthracis and Bacillus cereus biovar anthracis causing anthrax in Africa. PLoS Neglected Tropical Diseases ,14, e0008131. https://doi.org/10.1371/journal.pntd.0008131

Savransky, V., Shearer, J. D., Gainey, M. R., Sanford, D. C., Sivko, G. S., Stark, G. V., .. Skiadopoulos, M. H. (2017). Correlation between anthrax lethal toxin neutralizing antibody levels and survival in guinea pigs and nonhuman primates vaccinated with the AV7909 anthrax vaccine candidate. Vaccine , 35 (37), 4952-4959. https://doi.org/10.1016/j.vaccine.2017.07.076

Semenova, V. A., Schiffer, J., Steward-Clark, E., Soroka, S., Schmidt, D. S., Brawner, M. M., .. Quinn, C. P. (2012). Validation and long term performance characteristics of a quantitative enzyme linked immunosorbent assay (ELISA) for human anti-PA IgG. Journal of Immunological Methods , 376 (1-2), 97-107. https://doi.org/10.1016/j.jim.2011.12.002

Switzer, A., Munson, L., Beesley, C., Wilkins, P., Blackburn, J. K., \& Marker, L. (2016). Namibian Farmland Cheetahs (Acinonyx jubatus) Demonstrate Seronegativity for Antibodies Against Bacillus anthracis. African Journal of Wildlife Research , 46 (2), 139. https://doi.org/10.3957/056.046.0139

Turnbull, P. C. B., Doganay, M., Aygen, B., Lindeque, P. M., \& Mclaughlin, J. (1992). Serology and anthrax in humans, livestock and Etosha National Park wildlife. Epidemiology and Infection,108 (2), 299-313. https://doi.org/10.1017/S0950268800049773

World Organization for Animal Health (1997). Animal disease diagnosis, surveillance and notification, In: Terrestrial Animal Health Code. Paris: OIE.

WHO (2008). Anthrax in animals and humans. Fourth Edition. WHO, Geneva. URL: http://www.who.int/csr/resources/publications/AnthraxGuidelines2008/en/index.html.

Table 1: Seroprevalence of anthrax in lions sampled in protected areas and captive recreational game parks in Zimbabwe

\begin{tabular}{lllll}
\hline Wildlife Management Area & District & *Anthrax risk zone & Total tested & Total positive \\
\hline Hwange National Park & Hwange & $\mathrm{L}$ & 73 & 17 \\
Mana Pools National Park & Hurungwe & $\mathrm{L}$ & 11 & 2 \\
Save Valley Conservancy & Bikita/ Chiredzi & $\mathrm{H}$ & 6 & 1 \\
Malilangwe Wildlife Reserve & Chiredzi & $\mathrm{L}$ & 3 & 1 \\
Overall protected areas & Overall protected areas & $\mathrm{H}$ & 93 & 21 \\
Lion \& Cheetah Park & Norton & $\mathrm{H}$ & 6 & 1 \\
Chengeta Game Park & Chegutu & $\mathrm{L}$ & 5 & 1 \\
Antelope Game Park & Gweru & $\mathrm{H}$ & 6 & 0 \\
Bally Vaughan Game Park & Shamva & & 21 & 4 \\
Overall captive recreational parks & Overall captive recreational parks & & $\mathbf{1 1 4}$ & $\mathbf{2 5}$ \\
Grand Total & & & &
\end{tabular}

*Risk zone: $\mathrm{H}=$ high risk for anthrax, $\mathrm{L}=$ low risk for anthrax determined by Chikerema et al. (2013)

Source: 1 - Zimbabwe Parks \& Wildlife Management Authority, 2011; 2 - (Clegg, Turnbull, Foggin, \& Lindeque, 2007); 3 - OIE 1997.

+ There was no significant difference $(\mathrm{p}=0.852)$ in anthrax seropositivity between lions in high and those in low anthrax risk zones, and between lions in protected areas and those in captive game parks $(\mathrm{p}=0.951)$.

Table 2: Comparison of serological assays for anthrax in African lions from low and high anthrax region in 
Zimbabwe by anti-protective antigen (PA) ELISA and toxin neutralization assay (TNA).

\begin{tabular}{lllll}
\hline & & ELISA & ELISA & Total \\
\hline & & + & - & \\
TNA & + & 10 & 3 & $\mathbf{1 3}$ \\
& - & 7 & 7 & $\mathbf{1 4}$ \\
& Total & $\mathbf{1 7}$ & $\mathbf{1 0}$ & $\mathbf{2 7}$ \\
\hline
\end{tabular}

McNemar's $\chi^{2}$ test $=0.9, \mathrm{p}=0.343 ;$ Kappa $(\mathrm{K})$ statistic $=0.30 ; 0.08<\mathrm{K}<0.613$.

Figure 1. Map of Zimbabwe showing seroprevalence of anthrax in African lions sampled across the country.

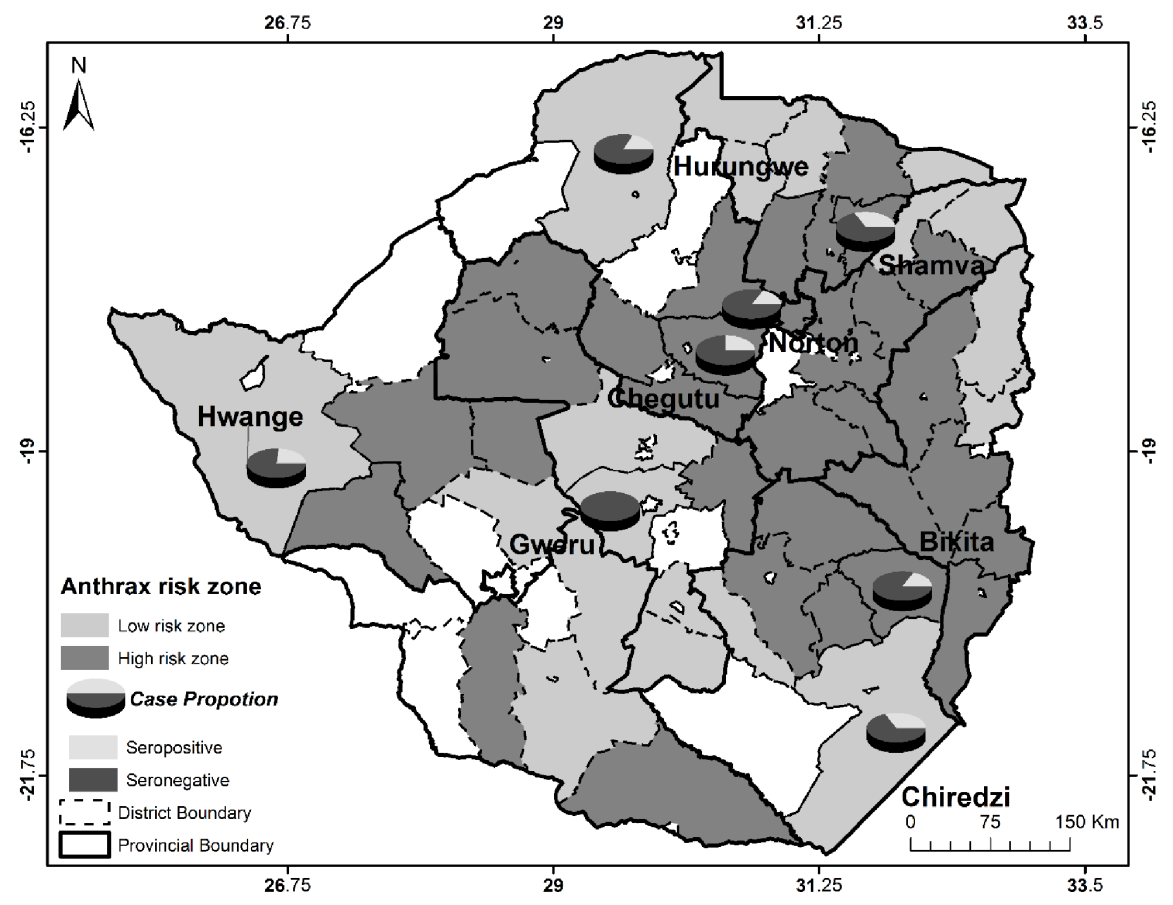


Figure 2. Map of Hwange National Park (Zimbabwe) showing distribution of anthrax positive lions in sampled areas.

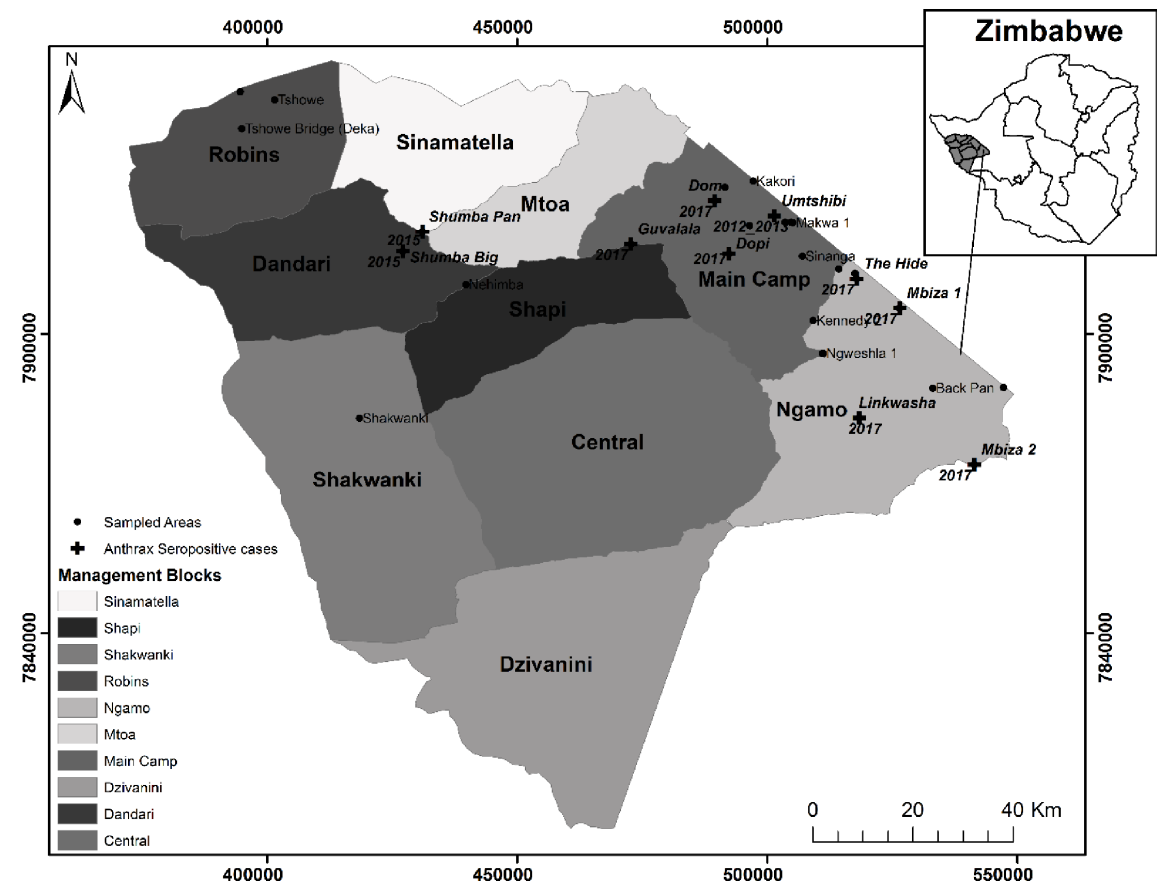

